\title{
Práticas e Políticas Internacionais de Colaboração Ciência-Indústria
}

\author{
Regina Gusmão
}

Assessora Técnica - FAPESP

\section{Resumo}

N as economias contemporâneas, o desempenho dossistemas deinovação estão, em grande medida, associad os à intensi dade è̀ eficácia das interações entre os diferentes atores envolvidos na geração e difusão denovos conhecimentose novas tecnologias. Essasinterações traduzem-se numa forma institucionalizada de "aprendizagem" mútua, que contribui para a criação de um estoquedeconhecimentoseconomicamenteúteis.

A partir desse postulado geral, o artigo propõe uma análise das principais evoluções na natureza das interações entrea pesquisa científica ea atividade industrial nos países desenvolvidos, focalizando as novas modal idades deintervenção dospoderes públicos voltadas ao favorecimento e ao apoio direto a essas colaborações.

0 artigo baseia-se, fundamentalmente, nas informações coletadas por dois estudos comparativos das experiências mais recentes observadas nos principais países industrial izados, realizados sob os auspícios da OCDE eda U nião Européia. As"relações ciência-indústria" $(\mathrm{RCI})$ prevalecentes nesses contextos são aqui examinadas sob a perspectiva das modalidades e da importância relativa dos dispositivos de cooperação existentes, dosnovosarranjosinstitucionais edas estruturas deincitação quevêm sendo amplamenteadotadas pelos podereslocais. Finalmente, são brevementeapresentadas al gumas implicações de política e as principais recomendações que emanam desses estudos.

Palavras-Chave | Transferência deTecnologia; Pesquisa em C ooperação; ColaboraçõesC iênciaIndústria; Sistemas N acionais de I novação; Política de C \& T

CÓdigOSJEL $\mid 03,038$ 


\section{ABSTRACT}

In contemporary economies, the performance of innovation systems is in alarge measure, associated to the intensity and efficiency of interaction among the different players involved in thegeneration and diffusion of new knowledgesand technologies. Theseinteractions aretranslated into a kind of institutionalized mutual "learning" that contributesto createa stock of economically useful knowledges.

From this general postulate, thepaper offers an analisys of themain developmentsin the nature of the interactions among scientific research and industrial activity in developed countries, focusing the new ways of public power intervention aiming to favour and to directly support thesecollaborations.

The paper is based essentially in the information gathered in two comparativestudies of the more recent experiences observed in the main industrialized countries, carried out under the patronage of OECD and theEU. The "industry-science relationships" (RCI) prevailing in these contexts arehereexamined under theperspective of themodalities and of therelativeimportance of theavailablecooperation dispositives, of thenew institutional arrangementsand of thestructures of incentivethat arebeing widely adopted by local powers. Finally, somepolicy implicationsand themain recommendations deriving from thesestudies are briefly presented.

KeYwords | Technological Change; Cooperative Research; ScienceIndustry Cooperation; Innovation National Systems; S\&T Policy

JEL-COdEs $\mid 03,038$

\section{Introdução}

As colaborações entre o setor público e o setor privado em matéria de pesquisa e desenvolvimento tecnológico ( $P \& D$ ) não têm uma história recente. Elas são características do sistema al emão desde o século XIX; no Reino U nido, jáno início do século XX, elas passam a assumir aforma de "missões de consel ho", realizadas por departamentos universitários de ciências e de engenharia junto às novas indústrias em expansão. M as foi nos Estados U nidos, no período da guerra fria, marcado por novas orientações de política induzidas pelo crescimento dos gastos deP\& $D$ no setor de defesa, quea antiga prática de colaboração entre as universidades e o mundo industrial ganha um novo e definitivo impulso. N o Japão do pós-guerra, essas colaborações passam a fazer parte integral dos 
grandes programas tecnológicos governamentais, voltadosà superação do atraso do país em determinados setores.

N osanos 1960 e1970, os paísesindustrializados são conduzidosa encorajar ainda mais as parcerias entre as instituições de $P \& D$ e o setor produtivo, com vistas a orientar os esforços de produção de novos conhecimentos para a promoção do desenvolvimento econômico local e, em particular, para a criação de novos empregos. No início dos anos 1980, o sucesso da política de transferência detecnologia e o notável crescimento industrial do J apão, somados à forte concorrência nos mercados mundiais de tecnologia, levaram os Estados U nidos afazer das "relações ciência-indústria" $(\mathrm{RCI})$ ? um componente-chave de sua política tecnológica e de inovação. $\mathrm{N}$ a maioria dos países, o estímulo à colaboração ciência-indústria passa então a ser visto como um importante instrumento de intervenção, transformando-senum dos pilares dos programas nacionaisdec \& T .

0 aumento significativo das $\mathrm{RCl}$ foi induzido por um conjunto de diferentes fatores, dos quais a literatura especializada destaca: a aceleração do ritmo de transição em direção a uma "economia baseada no conhecimento"; 0 desenvolvimento da globalização da economia e da concorrência entre firmas; as restriçõesorçamentárias ea redução generalizada dos financiamentos públicos à pesquisa; e a forte el evação dos custos das atividades de $P \& D$. A essa lista costuma-se ainda acrescentar: 0 estreitamento dos ciclos de vida dos produtos e, conseqüentemente, do horizontetemporal das atividades deP\& D; o processo de externalização das atividades de pesquisa das indústrias, em benefício dos institutos públicos e universidades; eas modificações nas regras de propriedade intelectual dos resultados das pesquisas financiadas com fundos públicos.

N os termos de Cervantes (1998), as colaborações entre os setores público e privado passaram a fazer parte integrante do "novo paradigma" da política tecnológica e de inovação dos paísesindustrial izados. As instituições de pesquisa e universidades têm sido cada vez mais constrangidasa orientar os resultados de seus esforços de $P \& D$ a serviço do aumento da competitividade da indústria nacional e do crescimento econômico. Para os poderes públicos, as principais

\footnotetext{
Tradução do termo "Industry-Science Relationships (ISR)", que é hoje amplamente utilizado na literatura especializada, particularmente em estudos comparativos das diferentes iniciativas de cooperação universidade-empresa que vêm sendo tomadas nos países desenvolvidos.
} 
vantagens dessa interação residem na melhor rentabilidade social da exploração ecomercial ização dos resultados das pesquisas financiadascom recursos públicos, e na diversificação das fontes de financiamento disponíveis. Para as empresas, além da redução dos riscose da repartição dos custos, as parcerias com instituições públicas autorizam 0 acesso à novas competências, a possi bilidade de absorção de conhecimentos e descobertas mais recentes, e a realização de pesquisas exploratórias em novas áreas, distintas daquelas de sua atuação principal.

A multiplicação das colaborações entre empresas, universidades e laboratórios governamentais vem transforman do o sistema de pesquisa e de inovação dos países industrial izados num sistema altamente cooperativo, com uma organização hierárquica do trabalho, uma distribuição de responsabilidades e de recursos, e submetida a esquemas de controle e de avaliação deseus resultados. N os termos de al guns autores, uma tranforformação radical da economia das instituições científicas está em curso: a "organização linear" da ciência e da tecnologia, baseada num conjunto pouco articulado de instituições relativamente isoladas, vem transformando-se num sistema de interações recorrentes; em conseqüência, o modelo de organização da $P \& D$ repousa atualmente sobre o conceito de coordenação e, localmente, sobre o de integração dos diferentes agentes públicos eprivados envolvidos (C assier, 1997). N esse sentido, o papel do poder público evoluiu do simples suporte financeiro, para a criação e manutenção da infra-estrutura necessária à comunicação eà cooperação entre esses agentes. Essa evolução tem conduzido autoridades e gestores a repensar a estrutura de financiamento da $P \& D$, as bases de sua avaliação, os mecanismos de seleção de prioridades, os instrumentos de estímulo à comercialização da pesquisa em cooperação. Em suma, o "gerenciamento da $P \& D$ " impõe-se como um recurso estratégico de fundamental importância para a inovação.

A experiênciainternacional revela que existem hojevariadasmodalidades de colaboração $C \& T$ entre o setor público e o setor privado, associadas a uma multiplicitade de dispositivos institucionais que foram criados para facilitar essa cooperação. M esmo ainda dispondo-se de um número limitado de informações agregadas e precisas sobre os verdadeiros impactos dessas iniciativas, já é possível constatar que esses dispositivos exercem um real efeito de al avancagem dos esforços de pesquisa e de inovação, além de importantes 
efeitos indiretos (como, por exemplo, o aperfeiçoamento da "operação em rede" e do fluxo de conhecimentos tácitos), suscetíveis de promover colaborações maisamplas e duradouras.

0 objetivo deste artigo é discutir as principais características e o alcance dascolaborações ciência-indústria prevalecentesnos paísesindustrializados, em particular nazona da OCD E. ${ }^{2}$ São focalizadosalguns aspectosrelativosànatureza e à importância relativa dos dispositivos de transferência adotados, ao quadro organizacional de apoio e às estruturas de incitação - de natureza financeira, gerencial e regulamentar - criadas para a gestão da pesquisa em cooperação.

Esses aspectos são aqui tratados em seções distintas. $N$ a seção 2, a seguir, são brevemente apresentados os fundamentos eos fatores principais que estão na origem do rápido desenvolvimento das $\mathrm{RCI}$, acompanhados deum panorama geral das modalidades prevalecentes nos países da OCD E. A seção 3 focaliza as principais tendências identificadas por estudos comparativos mais recentes, enfocando os novos arranjos, regulamentações emecanismos oficiais de apoio, quetêm sido amplamente adotados pelos poderes públicos. N uma perspectiva mais concreta eilustrativa dessas evoluções, a seção 4 detém-sena descrição das principais mudanças operadas nos sistemas públicos de pesquisa dos países europeus, em particular da França, do Reino U nido edaAlemanha, cujossistemas nacionais de pesquisa einovação repousam sobremodelos bastante contrastados. Finalmente, em função do caráter pioneiro edarelevância dos resultados obtidos pelo trabalho de dois anos desenvolvido pelo Working Group on Technology and Innovation Policy da OCDE ${ }^{3}$ - queconstitui uma das principaisfontes das informaç̃̃es tratadas neste artigo - a seção 5 indica brevemente as principais conclusões e recomendações que emanam desse trabalho, em especial no que tange às frentes abertas que demandam uma ação pública mais efetiva por parte dos países membros.

\footnotetext{
2 As informações e análises aqui apresentadas foram extraídas do relatório final de um estudo conduzido pela autora no âmbito de uma convenção firmada entre o Observatoire des Sciences et des Techniques (OST) e o Institut National de la Recherche Agronomique (INRA), ambos na França, com vistas a estabelecer um quadro de referências e fornecer insumos para a definição de uma "estratégia de cooperação com o setor industrial" para o INRA (OST, 2000).

3 Trata-se dos resultados do projeto Benchmarking Industry-Science Relationships, pilotado pelo Committe for Science and Technological Policy da OCDE, beneficiando-se de informações produzidas e fornecidas pelos Estados membros. O relatório final do projeto analisa as mudanças no papel das relações ciência-indústria (RCI) nos sistemas nacionais de inovação, propõe procedimentos para sua avaliação, apresenta indicadores comparativos sobre a configuração e a intensidade das $\mathrm{RCl}$ nos diferentes países, e sugere algumas good practices e recomendações para seu aperfeiçoamento (OCDE, 2002). Boa parte das experiências e dispositivos mencionados ao longo deste artigo foram extraídos dessa publicação.
} 


\section{Principais fundamentos e modalidades de cooperação ciência-indústria}

N o campo da pesquisa científica e tecnológica, a expressão "relações ciência-indústria" ( $\mathrm{RCl}$ ) refere-se a toda relação baseada na inovação onde os atores públicos e privados contribuem conjuntamente com os recursos financeiros, humanos e/ ou de infra-estrutura envolvidos no empreendimento. $\mathrm{N}$ essa perspectiva, as colaborações não constituem simples mecanismos de pesquisa contratual para subvencionar $\mathrm{P} \& \mathrm{D}$ industrial; elas traduzem-se em acordos formais ou informais, onde são traçados os objetivos gerais e específicos da pesquisa, assim como os aspectos relacionad os à comercialização dos resultados, fazendo intervir dois atores ou mais (C ervantes, 1998).

A intensificação e diversificação dessas interações são mais notadas e documentadas nos Estados U nidos, mas elas são também claramente identificáveis nos demais países, inclusive naqueles onde as trocas informais sempretiveram um papel preponderante(como naFrança eno Japão). Inúmeros trabalhos apontam as driving forces que estão na origem dessas tranfformações na forma de cooperação entre a pesqui sa fundamental, a pesquisa aplicada ea pesquisa industrial. D entre elas destacam-se (O CD E, 2000):

- a aceleração do progresso técnico ea expansão espetacular do mercado naqueles setores onde a inovação está diretamente associada ao avanço dos conhecimentos científicos de base (biotecnologias, tecnologias da informação, novosmateriais, etc.);

- o papel das novas tecnologias da informação e das comunicações, facilitando eagilizando as trocas entre a comunidade de pesquisadores;

- o aumento da demanda do setor industrial por colaborações com base científica, como requisito para a absorção de conhecimentos externose de natureza multidisciplinar;

- asexigênciasderedução doscustosdaP\&D nas empresas, eanecessidade de se garantir um acesso privilegiado e rápido a novos conhecimentos; - o desenvolvimento de um novo "mercado de conhecimentos", estimulando o financiamento ea gestão deuma vasta gama deatividades de comercialização e de transferência desses conhecimentos; 
- a entrada dos institutos de pesquisa e das universidades nesse novo mercado em explosão, estimulada pela baixa generalizada dos investimentos públicos em $P \& D$.

D eve-se ressal tar que esses fatores, ou driving-forces, operam de forma mais direta em determinados países do que em outros, e que eles não encontram os mesmos obstáculos nos diferentes contextos nacionais. Países como os Estados U nidos, que estão bastante avançados na construção de um modelo mais fluido e diversificado de $\mathrm{RCl}$, começam a ter que fazer face a novos tipos de problemas relacionados à regulamentação. N os países europeus, os sistemas de incitação estão claramente em expansão, mas seu desenvolvimento ainda é desigual.

Como mencionado anteriormente, a natureza e o alcance dos mecanismos oficiais deincitação das colaborações público-privado em matéria de pesquisa e desenvol vimento variam consideravel mente de um país a outro; el es compreendem desde a supressão de barreiras normativas relacionadas ao estatuto do pesquisador público, até o financiamento de grandes programas multilaterais. $\mathrm{N}$ o entanto, a experiência internacional mostra que, na maioria dos casos, as vias informais de comunicação são bem mais numerosas que as vias formais e que, em geral, elas têm se revelado decisivas para o sucesso das iniciativas oficiais. $\mathrm{N}$ os termos de certos autores, os mecanismos formais de condução das RCI correspondem apenas à face visível de um iceberg: a maior parte das colaborações, sobretudo nos países onde as estruturas de regulação são mais restritivas, se faz por intermédio de canais informais e indiretos, ou através de canais diretos "não-oficiais". As pesquisas nacionais de inovação inglesas, por exemplo, revelam que a metade das firmas manufaturei ras do país consideram os laboratórios universitários como uma importante fonte de conhecimentos para inovação, mas não mais do que $10 \%$ dessas empresas afirmam desenvolver com eles relações formais ou contratuais de colaboração (Senker, 1998).

$\mathrm{N}$ ão obstante, não resta dúvida de que as relações informais entre os pesquisadores, acadêmicos eindustriais que preval eciam num passado recente estão tomando progressivamente a forma de iniciativas e/ ou programas bem estruturados, cujas modalidades mais significativas são relacionadas a seguir. 
- A "pesquisa sob encomenda" (contract research)

Em toda a zona O CDE, observa-se uma forte tendência ao financiamento privado de atividades de pesquisa realizadasnasuniversidadesenas instituições de pesquisa, na forma deprojetos específicos, regidos por contratos definanciamento detalhados. 0 desenvolvimento da "pesquisa sob encomenda" explica-sepor uma série defatores, mas foi fortementeimpulsionado pela redução dos investimentos em pesquisa por parte das empresas, queprogressivamente passaram a externalizar uma boa parte de suas necessidades de $P \& D$. Por outro lado, através desses contratos, as empresas asseguram um acesso maisrápido aosnovos conhecimentos por intermédio de projetosmais direcionados às suas necessidades concretas. D e fato, a "pesquisa sob encomenda" ofereceàs empresas a possibilidadedeparticipar mais diretamente das pesquisas realizadas nos laboratórios públicos e de melhor definir, com os pesquisadores envolvidos, o que elas esperam como principais resultados.

Programas de trei namento e estági os de pesquisadores na indústria

(training \& mobility programs)

Programas de estágios de formação ou a permanência por período determinado de pesquisadores públicos em empresasindustriais constituem uma outraforma correntedecooperação ciência-indústria. Essainteração assumeformas diversas, como por exemplo: a alocação, a título temporário, de pesquisadores confirmadosou de doutorandosnaindústria, em missões específicas de pesquisa etreinamento; a utilização dasinstalações disponíveisna indústria para a condução de pesqui sas acadêmicas; a permanência detécnicoseengenhei ros das indústrias nas universidades, para o desenvolvimento deatividadesdocentese/ou a participação em projetos de longo prazo, que não poderiam ser conduzidos pela empresa de forma isolada; a al ocação de estudantes diplomados junto a tutores pertencentes ao mundo industrial. Essasiniciativas, geralmentefinanciadascom fundospúblicos, visam fundamentalmente 0 aprendizado do trabalho no meio industrial, 0 desenvolvimento de competências técnicas e de gestão específicas, a adoção de umaabordagem multidisciplinar na resolução de problemas e o estabelecimento decontatosinformais, quepodem favorecer futuros contratos detranferência de conhecimentos. $\mathrm{N}$ ote-se que, em alguns países, foram criados programas específicos direcionados às pequenas emédias empresas; o dispositivo holandês 
KIM , por exemplo, foi criado parafacilitar o recrutamento, por partedessasempresas, de pesquisadores qualificados para a realização de projetos de $P \& D$ específicos. $M$ ais recentemente, o procedimento TCS - Teaching Company Scheme, criado no Reino U nido em 1975, tem sevoltado às PM E, quechegaram a representar, em 2000, 90\% dos industriais mobilizados pelo programa. ${ }^{4}$ Um outro tipo de abordagem consiste em fomentar pesquisas de doutorado a partir de projetos desenvolvidos conjuntamente por uma universidade e uma empresa, como 0 programainglêsCASE - CollaborativeAwardsin Science\& Engineering; ao estudante éatribuída uma bolsa de estudos do Research C ouncil em complementação à parcela de recursos assegurada pel o parceiro industrial (O CDE, 2002).

Projetosde pesquisa em colaboração com o setor privado

sob financiamento público

Em quase todos os países são também mantidas linhas de financiamento público para projetos envolvendo parceiros do setor empresarial, voltados ao desenvolvimento de pesquisas orientadas para aplicações industriais, ou seja, os chamados projetos de "pesquisa pré-competitiva". N a maioria dos casos, essa cooperação assumea forma de projetos bilaterais, conduzidosnos laboratórios de uma empresa, de uma universidade ou de um instituto de pesquisa. Esses financiamentosvisam essencialmenteencorajar aformação deredes decolaboração entre pesquisadores dos setores público e privado, acelerar a transferência de tecnologia e a exploração comercial dos resultados das pesquisas, mobilizar as capacidades deinovação das PM E e, acima detudo, orientar os programas deação das universidadeseinstitutos de pesquisa para o atendimento das necessidades do setor produtivo e do mercado. Na Alemanha, por exemplo, o M inistério da Educação eda Pesquisa (BM BF) subvenciona projetos de pesquisa em cooperação entre pequenas empresas e universidades totalmente orientados para aplicações industriais, por intermédio da federação alemã de associações para a pesquisa industrial em cooperação (AIF). Já o programa LIN K, lançado no Reino U nido,

\footnotetext{
Esse dispositivo baseia-se em parcerias entre firmas e instituições de ensino superior para a formação e a transferência de conhecimentos. Os participantes do programa são financiados por intermédio de bolsas do governo alocadas nas universidades, complementadas por um suporte financeiro dos parceiros industriais. Esses fundos cobrem a contratação, por parte de uma empresa, de um ou mais pesquisadores com pós-graduação (conhecidos como TCS Associates), com comprovados conhecimentos em ciências ou engenharia, que devem trabalhar por um período de no mínimo dois anos nessa empresa, desenvolvendo projetos específicos. Uma pequena parcela de sua carga horária de trabalho (10\%) deve ser gasta na universidade colaboradora, em atividades acadêmicas.
} 
em 1986, promovea colaboração deempresas com pesquisadores deinstituições públicas para o desenvolvimento de projetos situados em áreas de importância estratégica particular. ${ }^{5}$

- "Consórciosdepesquisa"

Além dos projetos bilaterais ou colaborações de natureza mais dirigida, como osacima mencionados, os governos dos países centraistambém co-financiam projetos de cooperação em larga escala, baseados na associação de um grande número de instituições de pesquisa e de empresas industriais, para 0 desenvolvimento de tecnologias em setores de ponta ou para a condução de pesquisas degrandealcance, decusto particularmenteelevado. U m dosmelhores exemplos desse tipo de cooperação refere-se aos projetos multilaterais financiados no âmbito dos programas de pesquisa e desenvolvimento tecnológico da U nião Européia(EC , 1997), queserão examinadosmaisadiante, na seção 4.3. Jána effera nacional, o programa japonês ERATO, administrado pela JST-Japan S\& T Corporation, foi pionero na promoção degrandes projetos depesquisamultilaterais, associando industriais, universidadese poder público; no âmbito desse programa, osconsórcios depesquisa reagrupam de 10 a 20 membros, liderados por um project leader, encarregado do desenvolvimento deatividades de pesquisa fundamental por um período máximo de cinco anos. ${ }^{6}$ No caso dos Estados Unidos, 0 desenvolvimento e suporte a consórcios de P\& $D$ mais amplos são objeto de um programa específico denominado Advanced Technology Program (OCDE, 1998b).

"Centros de excelência"

Por intermédio do financiamento a instalações ou grandes equipamentos de pesquisa, geralmentebaseados em universidades ou institutos de pesquisa, os países procuram criar "centros de excelência" que são, em geral, de natureza multidisciplinar. De uma maneira geral, os poderes públicos asseguram um financiamento por um período determinado (de três a dez anos), com uma

\footnotetext{
5 LINK é o principal dispositivo governamental inglês de promoção da cooperação em matéria de pesquisa pré-competitiva entre empresas industriais e instituições científicas, voltado à inovação de produtos, processos ou serviços. Ele concentra-se em áreas de particular importância estratégica para a economia do país. Cada subprograma (em áreas como engenharia médica, novos sistemas de comunicação, veículos do futuro, ciência avançada em alimentação, etc.), financia um conjunto de projetos envolvendo equipes de P\&D do setor público e do setor industrial. A esse respeito, ver Senker et al. (1999).

6 O financiamento é da ordem de centenas de milhões de yen, por ano, incluindo despesas de pessoal relativas aos pesquisadores envolvidos, que são empregados pelo JST. Para pesquisadores provenientes do setor industrial, que representam cerca de $40 \%$ do total de beneficiários, é estabelecido um contrato temporário de transferência (OCDE, 2002).
} 
contrapartida equivalentedaindústria. Foi nosEstadosU nidosqueuma das mais antigas iniciativas dessetipo foi implementada: trata-se da criação dos U niversityIndustry Research Centers (UIRC), promovidospela N ational ScienceFoundation, quejá financiou a criação demais de 50 entidades dessetipo, em diferentessetores. 0 paístambém estimulou o desenvolvimento dosEngineering Research C enters edosScienceand Technology Centers, dosquais os industriaispodem vir a tornarse membros mediante uma contribuição anual; esta Ihes assegura o direito de participar da seleção deprioridades da carteira deprojetos, eo acesso aos resultados obtidos. Esse tipo deabordagem, que se apóia na criação de centros de pesquisa cooperativa de certa forma "autônomos", consiste em criar uma interface institucional que possa vir a tornar-se um lugar de encontro estável para as colaborações. N essesentido, a oficina nacional para o desenvolvimento industrial etécnico da Suécia, NUTEK, implementou um dispositivo definanciamento de centros de competência nas universidades einstituições de pesquisa, dosquaisas empresas industriais participam ativamente; existem atualmente 30 centros de excelência N UTEK em oito universidades e institutos de tecnologia do país. $\mathrm{Na}$ Finlândia, foram criados 11 centros de competência, voltados ao estímulo da cooperação entre as PM E, as autoridades locais, os parques científicos, as universidades e os institutos de pesquisa. Na Áustria, o programa Kplus implementou cerca de 20 centros desse tipo, financiados a $60 \%$ com fundos públicos; já na H olanda optou-se por uma abordagem mais seletiva, através da criação de quatro Technological Top Institutes, com o objetivo de encorajar a cooperação C\&T dealto nível (O CDE,1998b e2002).

\section{Transformações recentes das relações ciência-indústria na zona OCDE}

0 rápido desenvolvimento das relações ciência-indústria observado nos países industrializados veio acompanhado de transformações importantes nos objetivos e nas estratégias das partes envolvidas. Em termos gerais, os primeiros objetivos dos poderes públicos na promoção das $\mathrm{RCl}$ é o estímulo e 0 aperfeiçoamento do processo de geração e difusão de conhecimentos, 0 fortal ecimento do retorno social dosinvestimentos públicosem $P \& D, 0$ aumento 
da produtividadee o crescimento econômico nacional. N o entanto, osobjetivos reais são menos abstratos; envolvem questões relacionadas à situação do mercado detrabalho, à seleção deprioridades definanciamento, à escolha deinstrumentos de política tecnológica eà gestão do sistema nacional de pesquisa e deinovação.

As diferentes categorias de instituições públicas de pesquisa, por sua vez, val orizam as relações com os industriais por razões diversas. Fundamental mente, as universidades visam atualizar e ajustar a estrutura disciplinar e obter apoio técnico e financeiro - do setor privado para manter suas capacidadesinternas de pesquisa e desenvolvimento. Já as chamadas leading research universi ties adotam objetivos mais ambiciosos, como a criação dealianças estratégicas com as grandes empresas para consolidar sua posição nas redes de inovação e garantir sua parte nosmercados denovos conhecimentos, em rápida expansão. Em contrapartida, universidadesmenores, queenfrentam atualmenteuma concorrênciamaisacirrada para a obtenção de recursos públicos, procuram transformar uma parte de seus departamentos acadêmicos e de pesquisa em unidades de apoio às atividades comerciais e de gestão dos "projetos sob encomenda". Já os institutos públicos de pesquisa, sobretudo os especializados, quesempre mantiveram uma colaboração estável erelações privilegiadas com aindústria, procuram diversificar suasatividades paraalém desuasáreastradicionais deatuação, às vezesem estagnação. Atualmente, eles sevêem obrigadosa promover adaptaçõese ajustes para enfrentar as exigências das novas indústrias baseadas no conhecimento, onde as pequenas empresas de al ta tecnologia desempenham um papel central.

Q uanto ao setor privado, as pesquisas nacionais deinovação (ou I nnovation Surveys, realizadas periodicamente nos diferentes paí ses a partir demetodologias comuns propostas por instâncias internacionais como a Comissão Européia ou a $O C D E$ ) revelam que, face ao risco de falta persistente de trabalho altamente qualificado, a melhoria do acesso a recursos humanos qualificadoséconsiderado como o benefício mais importante que os industriais esperam das colaborações com as instituições públicas de $P \& D$. Porém, um acesso privilegiado a novos conhecimentos e 0 aperfeiçoamento dos esforços próprios de $P \& D$ passaram também a adquirir uma importância estratégica particular. ${ }^{7}$

\footnotetext{
7 A título de ilustração, estima-se que cerca de três quartos das referências de publicações científicas listadas nas patentes americanas envolvem pesquisadores do setor acadêmico. Ademais, segundo Mansfield (1998), aproximadamente um terço dos novos produtos, de acordo com o setor, não poderiam ter sido lançados sem o input direto de pesquisas recentes desenvolvidas nas universidades.
} 


\subsection{Comercialização dos resultados da P\&D}

Considera-sequea mudança mais espetacular nas relaçõesciência-indústria observadasnaúltima décadaéo crescenteaumento decertas modalidadesformais de transferência de conhecimentos e sua transformação em bens econômicos, particularmente através do depósito de patentes e da criação das chamadas spinoffs, queserão tratadasna próxima seção.

N osEstadosU nidos, ao longo dosanos 1990, asuniversidadeseosinstitutos depesquisa americanosmaisque dobraram seus esforços depatenteamento. N esse país, o depósito depatentes pelasuniversidades aumentou maisrapidamentequea média nacional, edeformamais acentuada queo aumento dos dispêndiosdeP\& $D$ nessas instituições. No entanto, os Estados U nidos já não são osúnicos a obterem resultadostão positivos; naAlemanha, por exemplo, a taxa desolicitação depatentes ondeos inventoressão professores universitários não cessa de crescer desdeosanos 1980, chegando a atingir, em 1995, 4\% do total de solicitações (O CDE, 2000).

A propriedadeintelectual éfonte de numerosos conflitos entre a pesquisa pública e o mundo empresarial. H istoricamente, osEstadosU nidos foram o país quemais levou adiante a proteção formal dos direitos de propriedadeintelectual daP\& D financiada com recursos públicos. A lei Bayh-D olePatent and Trademark Amendments Act, de 1980, permite aos participantes de pesquisas financiadas com fundos federais depositar solicitações de patentes e conceder licenças de exploração a terceiros. Essa possibilidade suscitou um forteaumento no número deparcerias ecolaborações, muito embora ela prenuncie, segundo os especialistas, uma evolução preocupante: as universi dades passam a semostrar mais propensas a aceitar restrições significativas para a publicação de pesquisas conduzidas juntamente com os industriais, o que pode bloquear a difusão de importantes descobertas científicas enquanto a solicitação de patentesnão for depositada.

0 aspecto principal a salientar aqui équeasmodificaçõesnasleis depatentes nosEstadosU nidos, etambém em outros países europeus, principalmentea partir demeados dos anos 1990, conduziram à criação, no interior das universidadese dos institutos de pesquisa, de novas agências intermediárias para a formalização das interações com o setor privado. Essas unidades especiais são incumbidas da exploração comercial, da concessão delicençasou da transferência detecnologia, interagindo diretamente com os parceiros empresariais desde a negociação dos 
contratos até o estabelecimento de disposições finais relativas a concessões e contrapartidas. Em outros países, como veremos na seção 3.4., instituições de ensino superior procuram igualmentecriar estruturasintermediárias externas para o gerenciamento doslaços cada vez mais complexos estabelecidos com o mundo industrial.

À imagem do queéfeito nosEstadosU nidos, amaior partedospaíseseuropeus concedea propriedadedosresultadosdaspesquisas financiadas com fundospúblicos à própria instituição executora, e não ao inventor. ${ }^{8} 0$ bserva-se porém uma certa heterogeneidadea esserespeito, resultantedo complexo tecido deregulamentações existentessobreamatéria. $\mathrm{N}$ aAlemanha, por exemplo, osinstitutosgovernamentais adquirem o direito depropriedadeintelectual sobreapesquisa financiadacom fundos públicos; nas universidades, entretanto, é o professor ou pesquisador responsável queadquireesses direitos. No Reino U nido, observam-sediferentestiposderegras, mas a tendência, principalmente nos novos polytechnics, é a de que o título de propriedadeseja transferido à instituição enão ao pesquisador.

0 crescente aumento dos depósitos de patentes tem gerado importantes conseqüências na orientação geral daspolíticasnacionais depesquisa edeinovação. Real izado com o intuito demel hor conhecer eaprofundar essas questões, o estudo comparativo da O CDE mencionado na introdução desteartigo, ecujosresultados finais foram recentemente publicados no volumeB enchmarking I ndustry-Science Relationships(O CDE, 2002), abrem novas pistas para análise e para estudosmais aprofundados. N os parágrafos que se seguem, destacamos as que nos parecem particularmente relevantes.

- À exceção deal guns casos extremos, as receitas provenientes delicenças não reduzem demaneirasignificativa a necessidade de obtenção de outras fontes de financiamento por parte das instituições públicas de pesquisa. N osEstados U nidos, por exemplo, essas receitas representam, em média, não mais do que $3 \%$ dosfundos depesquisa dasuniversidadesemenos de $2 \%$ das despesas de $P \& D$ dosinstitutos públicos.

- O depósito de patentes nem sempre é um bom indicador do nível de produção científica deuma instituição ou grupo de pesquisa. A distribuição

8 Segundo as disposições do Bayh-Dole Patent and Trademark Amendments Act (Mowery, 1999). 
do conjunto de patentes solicitadas pelas universidades é fortemente influenciada pela performanceespetacular dedeterminados setores; ademais, de uma maneira geral, a mai or parte dos ganhos com licenças provém de um número restrito deinvençõesquese verificaram bem-sucedidas. A título deilustração, em 1997, a duplicação das receitas provenientes depatentes do maior organismo público depesquisa francês, o CN RS - CentreN ational dela RechercheScientifique, foi em grandeparteresultanteda exploração de um só produto (o Taxoter) que, sozinho, totalizou quase $40 \%$ dessas receitas totais.

- O sefforçosdo poder público para estimular efavorecer a comercialização dos resultados das pesquisas devem ser interpretados à luz do contexto mais geral decada país. Asmudançasno regimededireitosdepropriedade intelectual nos Estados U nidos foi um fator determinante para o rápido crescimento das atividades de patenteamento das universidades americanas nos últimos anos; no entanto, esse aumento deve-se também, em grande parte, a uma velha tradição de colaboração com o setor empresarial privado, facilitada pelo estatuto autônomo da pesquisa universitária no país.

- A experiênciainternacional revelaaindaquea contribuição maisimportante dos esforços de patenteamento das universidades no processo de inovação não é o fortalecimento da pesquisa pública em termos comerciais, mas sobretudo a melhoria do fluxo deinformaçõesa respeito da disponibilidade elocalização deresultados depesquisas comercialmentepertinentes.

\subsection{A criação de spin-offs}

N a maioria dos países da zona OCDE, iniciativas governamentais de financiamento eapoio à criação deempresasnascidas da colaboração universidade indústria têm se multiplicado. Tratam-se, em geral, de pequenas empresas de basetecnológica criadas por pesquisadores do setor público, do setor industrial, ou de professores universitários, cujas atividades apóiam-se, ao menos num primeiro momento, nos resultados depesquisas que sebeneficiam deuma licença deexploração. 
Aschamadas spin-offs 9 constituem a "rota empresarial" da pesquisa pública e, como tais, elas despertam muita atenção dos governantes. D e uma maneira geral, essetipo de parceria évisto como um dosfatoresqueexplicam performances espetaculares de determinadas empresas baseadas no conhecimento, especialmente em setores como o de biotecnologia.

0 elevado interesse pelas spin-offs levanta porém, de acordo com o estudo da OCDE, al gumas questões relativas ao seu real impacto sobreo avanço das $\mathrm{RCI}$ e sobre as "melhores práticas" de incitação por parte dos poderes públicos. D estacamos, a seguir, as que consideramosmaisilustrativas.

- A contribuição dasspin-offsresultantes da pesquisa pública para o processo de inovação não é tão direta como se é levado a concluir. Atualmente, o número denovas firmas dessetipo criadas a cada ano éainda bem modesto. N os países europeus, elas representam não mais do que entre $10 \%$ e $30 \%$ da atividadetotal dasempresasemergentes debasetecnológica. $\mathrm{N}$ os Estados U nidos, ao final dosanos 1990, as spin-offsconcentravam não mais do que $10 \%$ das licenças negociadas pelas universidades. Para os especialistas, as spin-offsteriam portanto um papel específico ediferentedaqueledas outras empresas de base tecnológica: elas constituem, antes detudo, o núcleo ou ponto focal de clusters de firmas inovadoras, formados ao redor de universidadese empresasindustriais.

- A criação despin-offspelo setor público não éum fenômeno general izado. Ela é mais importante em determinados países do que em outros: nos Estados U nidos, por exemplo, a taxa de criação dessas firmas é de três a quatro vezes maior do que a registrada em outros países da zona O CDE. Além disso, elas ainda não abrangem uma gama relativamente variada de setores; ao contrário, elas estão extremamente concentradas em determinadoscampos, com destaque para a tecnologia da informação ea biotecnologia.

\footnotetext{
Na definição adotada pela OCDE, spin-offs são: (i) firmas criadas por pesquisadores do setor público (pessoal do staff, professores ou pós-doutorandos); (ii) empresas emergentes que dispõem de licenças de exploração de tecnologias geradas no setor público; (iii) empresas emergentes sustentadas por uma participação direta de fundos públicos, ou que foram criadas a partir de instituições públicas de pesquisa.
} 
- A estrutura institucional dos sistemasnacionais de inovação, sobretudo o peso das universidades e dos institutos públicos de pesquisa, varia consideravelmenteentre os países. O s dispositivos oficiais einstrumentos destinados a favorecer a criação de spin-offsdevem portanto levar em conta essas particularidades de natureza estrutural, sob pena de tornarem-se totalmenteinadequadoseinoperantes.

- D euma maneira geral, os países estão cada vez mais conscientes de que a criação ou a melhoria do ambiente para a comercialização das atividades deP\& $D$ favorecem sobremaneira a criação de novas spin-offs. N o entanto, de acordo com os analistas, a verdadeira questão que se coloca é a de se saber até que ponto os poderes públicos estão dispostos a investir num mecanismo que favorece apenas um conjunto específico de empresas, em detrimento de outros dispositivos quefavorecem a criação deempresas em geral. Por outro lado, a experiência de alguns países revela que há certos obstáculos específicos à criação de spin-offs que só podem ser resolvidos por intermédio de reformas, de natureza normativa ou procedimental, promovidas pelo poder público. Como, por exemplo, as relativas ao estatuto dos pesquisadores do setor público e ao reconhecimento de seus esforços de transferência e de comercialização, como serátratado a seguir.

\subsection{Modificações no estatuto dos pesquisadores do setor público}

A rigidez do estatuto e do regime de trabalho a que são submetidos os pesquisadores do setor público, principalmente no que se refere à mobilidade institucional e à possibilidade de envolvimento mais direto em atividades comerciais, prevalecena maioria dos países como um dos principais obstáculosàs $\mathrm{RCl}$. Em certos casos, como nos Estados U nidos, no Reino Unido, na H olanda, na Austrália e no Canadá, as restrições são menores e a liberdade de ação e de circulação dos pesquisadores mais elevadas. $\mathrm{N}$ a França, na Itália, no Japão e na Bélgica, ao contrário, as regulamentações sobre o raio deação dospesquisadores públicose universitáriossão bem mais restritivas.

A insuficiênciaou inadequação dosindicadores disponíveissobreessaquetão 
ainda dificultam comparações internacionais. A análise de dados nacionais relativosà mudança deemprego dospesquisadores edos professoresuniversitários fornece porém algumas indicações interessantes. N os Estados Unidos, por exemplo, estima-se que os pesquisadores e engenheiros mudam de emprego a cada quatro anos, e ainda mais freqüentemente os que atuam na área das tecnologias da informação. N o Japão, ao contrário, somente $20 \%$ dos engenheiros mudam de emprego ao longo de sua carreira. Além dos aspectos culturais associados a uma tradição de empregos vitalícios isso se explica, em grande parte, pela prevalência de importantesnormas restritivas ao intercâmbio eà circulação dos diferentes atores do sistema nacional de inovação.

A flexibilidade no mercado de trabalho, inclusive no que tange às remunerações eà possibilidade de transferência de esquemas de aposentadoria, podefacilitar sobremaneira a mobilidade- tanto funcional como geográficado pessoal do setor de $P \& D$. N o entanto, prevalecem, em vários países, importantes barreiras normativas ou procedimentais, que envolvem, basicamente:

a) a legislação relativa ao emprego público, que incide sobre os pesquisadores vinculados aos institutos ou agências governamentais, sobretudo em países como a França, a Itália ea D inamarca; atéum passado recente, os pesquisadores públicos franceses e japoneses, dentre outros exemplos, eram colocados na impossibilidade de realizar atividades comerciais em razão do seu estatuto público;

b) as regulamentações relativas a alocações temporárias e estágios de treinamento, quesão geralmente específicas a cada instituição. $\mathrm{N}$ a maioria dos países europeus, as transferências temporárias ea atribuição de ano sabático concernem exclusivamentea realização deatividades de pesquisa ou acadêmicas em outras universidades; em um número reduzido de casos, como nas universidades inglesas, os professores são autorizados, sob certas condições, a trabal har temporariamentenaindústria;

c) as regulamentações relativas à remuneração dos pesquisadores e professores do setor público. $\mathrm{N}$ a Alemanha, por exemplo, os professores universitários e o pessoal dos institutos de pesquisa são autorizados a possuir uma segunda ocupação remunerada, embora limitada a $20 \%$ de 
sua jornada de trabalho e, mesmo assim, somente após uma aprovação administrativa específica.

Vale ainda salientar que as normas existentes, ainda que em processo de revisão e atualização, continuam tendo que enfrentar constrangimentos concretos de aplicação prática. A possibilidadededisponibilizar um pesquisador ou professor universitário para ser alocado em uma outra função ou entidade, principalmente por longos períodos, depende do sucesso em se encontrar um substituto adequado. Por outro lado, os afastamentos temporários tendem a ser reservados a professores titulares ou a pesquisadores dispondo de contratos permanentes, enquanto que a propensão a transferências temporárias tende a baixar com a idade, eisso em todas as categorias profissionais. Em outras palavras, a simples autorização para assumir uma segunda atividade ou função não é suficientepara estimular os pesquisadores, seela não éacompanhada de mudanças na forma como as promoções e as remunerações são garantidas.

A pesar da persistência de importantes barreiras, observa-se nos países da U nião Européia evoluções bastante positivas no sentido de se garantir uma maior autonomia das universidades e institutos de pesquisa, e um certo relaxamento das regrasque regem as parcerias com o setor privado. $\mathrm{N}$ aFrança, a nova Lei de I novação de 1999, passa a autorizar o engajamento temporário de pesqui sadores e professores universitários na indústria, com a possibilidade de obtenção de uma remuneração secundária. O utros países vêm adotando iniciativas complementares, como a criação de programas de formação - epossível futura instalação - de estudantes universitários em pequenas emédias empresas. Essas ações visam também estimular a modernização de PM E em setores tradicionais, que não dispõem de recursos financeiros e de infra-estrutura suficientes para atrair pessoal mais qualificado em novas tecnologias.

Ainda pouco explorada pelo conjunto depaíses, a remuneração individual a pesquisadores por seus esforços de comercialização constitui-se num outro importante instrumento para o avanço das $\mathrm{RCl}$. Um dispositivo inglês, denominado Realizing O ur Potential Awards Scheme, premia pesquisadores universitários que obtêm financiamentos da indústria para o desenvolvimento de projetos com subvenções suplementares para a realização de novas pesquisas exploratórias (G eorghiou, 1998). N a maioria dos países, porém, as regras 
restritivas sobre remuneração suplementar, sistemas de promoção, prêmios ou recompensas, etransposição de regimes de aposentadoria, com as quais se deparam os pesquisadores do setor público continuam representando um dos maiores obstáculos para o fortalecimento das RCI.

\subsection{Novos arranjos institucionais de comercialização e transferência de tecnologia}

0 aperfeiçoamento dosmecanismos de incitação ede suporteàs RCI têm induzido transformações institucionaisimportantes, tanto no conjunto do sistema nacional depesquisa e deinovação, como na estrutura organizacional interna das entidades envolvidas.

O s resultados do estudo comparativo apoiado pela O CDE revelam que, de uma maneira geral, as diferentes soluções de arranjos institucionais colocados em prática adequam-se a trêsformatos básicos $(0$ CDE, 2002). Em um primeiro tipo deabordagem, novas oficinas detransferência detecnologia e de concessão delicenças passam a fazer parteda estrutura interna dasuniversidadeseinstituições depesquisa. Essas oficinas- departamentos, unidades ou agências intermediárias - beneficiam-sedeuma vantagem particular: oscustosfixos de pessoal eoscustos operacionaissão absorvidospela instituição de vínculo. A proximidadefísica com os pesquisadores garanteainda o estabelecimento de relações mais estreitas entre os executores deatividades deP\& $D$ eos serviços de comercialização.

U m segundo formato é caracterizado pelo estabelecimento de agências "subsidiárias", que gozam de um certo grau de independência. Sua principal vantagem é a diminuição de riscos de conflitos de interesse entre o mundo da pesquisa e o dos operadores das atividades de comercialização. As subsidiárias dispõem de uma elevada autonomia administrativa e financeira, o que facilita suas relações com os beneficiários potenciais das licenças. $N$ ovas agências de transferência dessetipo estão setransformando, desimples estruturasdesuportee apoio legal que eram no passado, a verdadeiras "agências de negócios", com a missão de buscar novas oportunidades de comercialização, inclusiveno exterior (como éo caso das atividades desenvolvidas pela oficina detransferência do M IT, nosEstados U nidos). D estaca-seainda, naAlemanha, o importantepapel do PST - Fraunhofer Patent Centre for German Research que, além de ser o órgão 
responsável pelo registro e proteção dos direitos de propriedade intelectual das pesquisas realizadas em todososinstitutos daFraunhofer Gesel Ischaft, tem atuado como o principal parceiro da comunidade de pesquisadoresem geral, fornecendo uma variada gama de serviços voltados ao sucesso comercial de novos produtose tecnologias. ${ }^{10}$

Por fim, o terceiro formato baseia-se na intervenção de intermediários externos - públicos ou privados - que são chamados a assumir os esforços de transferência e de concessão delicenças resultantes dosesforçosdeP\& $D$ realizados nas universidades, institutos ou empresas. Como exemplos de intermediários privadospodemoscitar o Research Corporation Technologiese, maisrecentemente, o Internet-based Platforms, ambos criados nos Estados Unidos. D entre os intermediários públicos, destaca-se a agência austríaca de exploração de patentes, TECM A, que avalia potenciais invenções geradas nas universidades (OCDE, 2002:65). Jáa importanteexperiência do J apão repousa na criação de uma ampla rededeoficinas detransferência detecnologia, denominadasTechnology Licensing O ffices (TLO ), encarregadas da avaliação eeventual comercial ização dosresultados de pesquisas realizadas por universitários. O sTLO também dispõem de um de mandato específico para apoio às pequenas e médias empresas, a exemplo dos Intellectual Property Services O ffices, criados no Canadá (O CDE, 2002:176). Privilegiando a intermediação na esfera regional, valefinalmentedestacar a operação em rede dos CRITT - Centres Régionaux d'Innovation et Transfert de Technologies, criadosnaFrança no final dosanos 1980, voltadospara a prestação de serviços de transferência de maneira fortemente articulada junto às PME, institutos de pesquisa euniversidades.

\section{Notas sobre o processo de reestruturação do setor público de P\&D nos países europeus}

As importantes transformações que vêm ocorrendo no processo de desenvolvimento tecnológico eindustrial das economiasavançadas, têm levado os países a rever suas políticas em matéria de pesquisa e deinovação, ea promover

${ }^{10}$ A esse respeito ver www.fraunhofer.de/english/profile/institute/pst 
profundas reestruturações na forma deorganização ededistribuição dos esforços internos deP\&D.

U m estudo intitulado European Comparison of Public Research Systems, realizado em 1999 no âmbito do programa TSER - Target Socio-Economic Research, da União Européia, recolheu e sistematizou um conjunto de informações relativas às experiências de 12 países membros (Senker et al., 1999). Conduzido por um conjunto de equipes de pesquisadores, sob a coordenação do SPRU - Science Policy Research U nity, o estudo apresenta um rico panorama das evoluções mais recentes e principaistendências do setor público de pesquisa edeinovação no continenteeuropeu. N esta seção propõe-seuma brevediscussão dos resultados mais importantes obtidos pelo estudo, com destaque para as experiências concretas da França, da Inglaterra eda Alemanha, enfatizando suas particularidades e eventuais semelhanças.

\subsection{A pesquisa pública na Europa: dois paradigmas e evoluções recentes}

Em quase todos os países da União Européia (UE), os investimentos públicosem $P \& D$ visam, acima detudo, o avanço do conhecimento ea promoção do desenvolvimento econômico nacional eregional. $\mathrm{H}$ istoricamente, esses são os pilares desustentação das políticas nacionais deensino superior ede pesquisa. D e todos os países, a Alemanha foi quem maisinvestiu no avanço do conhecimento, em detrimento da pesquisa mais aplicada, voltada às necessidades do setor produtivo. O s demais países, em maior ou menor grau, sempre situaram-se entre esses dois pólos. A partir dos anos 1980, no entanto, a inovação e a transferência de tecnologia voltadas ao crescimento econômico passaram a assumir uma posição de destaque nas políticas e programas governamentais de ação de todos os países.

A Europa não dispõe de um modelo único em matéria de financiamento público à $P \& D$. Entretanto, os autores distinguem basicamente dois sistemas distintos, que podem até coexistir em certos casos:

1) o modelo de financiamento baseado em organismos do tipo R esearch Councils, quetransferem fundosàsuniversidades, naforma desubvenções, 
para o desenvolvimento de atividades de pesquisa, que são selecionadas na base do competitive peer review. Esses fundos complementam os recursos próprios das universidades, que garantem a infra-estrutura necessária para a real ização das atividades acadêmicas e de pesquisa, e o pagamento de uma parte dos salários dos professores. Sob esse modelo são reagrupados os sistemas universitários de países como o Reino U nido, a Suécia, a D inamarca ea N oruega; 11

2) o modelo de financiamento baseado em block grants, onde os salários dos professores cobrem integralmenteas atividades deensino ede pesquisa das universidades. Estas dispõem de fundos específicos para $P \& D$, e decidem de forma independente sobre a repartição ea alocação interna desses fundos, que são em geral complementados por recursos provenientes de agências governamentais defomento, do setor privado e da U nião Européia. As universidades alemãs, espanholas e italianas funcionam fundamentalmente sob esse regime. Em vários países, esse modelo de financiamento é também adotado pelos laboratórios governamentais e institutos de pesquisa especializados, sob controle financeiro eoperacional de ministérios setoriais. Em algunscasos, os block grants para atividades de P\&D provêm do estado ou das regiões; na Alemanha, por exemplo, as políticas de educação ede promoção da C\& T são tradicionalmente de responsabilidade exclusiva dos $L$ änders.

N os países europeus, coexistem fontesmúltiplas definanciamento à $P Q D$ : departamentos e agências governamentais, instituições sem fins lucrativos, empresas privadas e, mais recentemente, os fundos provenientes da União Européia. N a maioria das vezes, essa proliferação de fontes de financiamento não foi, porém, acompanhada de um esforço particular de coordenação. Tradicionalmente, a França parece possuir o sistema mais coordenado e centralizado, baseado na adoção de uma estratégia de conjunto e de programas

\footnotetext{
11 O sistema francês é, desse ponto de vista, bastante particular: organismos como o CNRS - Centre National de la Recherche Scientifique e o INSERM - Institut National de la Recherche Médicale, que poderiam ser considerados como verdadeiros Research Councils, não financiam diretamente pesquisadores individuais e seus projetos. Na verdade, eles associam-se a determinados departamentos ou unidades das universidades (que passam a denominar-se unités mixtes ou unités associées), contribuindo com uma parte dos efetivos e dos recursos materiais para sua operação.
} 
de ação plurianuais, implementados por diferentes ministérios. No extremo oposto, o sistema descentralizado alemão quase não dispõe de dispositivos específicos de coordenação do sistema definanciamento.

A principal tendência identificada pel os autores do estudo acima citado refere-se à lenta mas constante erosão dos sistemas de financiamento de tipo block grants, em contraposição ao fortalecimento dos sistemas baseados na atribuição de subvenções específicas para $P \& D$ e de fundos provenientes de instâncias regionais. Porém, seja qual for o sistema definanciamento preval ecente, na quase totalidade dos países daU E, os atores públicos da $P \& D$ encontram-se atual mente submetidos a uma forte pressão para aumentar a parcela dos fundos provenientes de fontes externas (Senker et al., 1999).

Vale notar que, com as reformas dos sistemas educacionais promovidas no bojo da expansão da U nião Européia, um número crescente de entidades (como os antigos colleges of education ou polytechnics) passou a integrar o sistema de ensino superior e a obter a permissão para desenvolver atividades deP\& $D$. Conseqüentemente, nos países dispondo de uma estrutura de pesquisa antiga e sólida, como o Reino U nido, a Alemanha, a Suécia e a N oruega, essa evolução acirrou a concorrência entre os diferentes atores para aceder a fontes externas de financiamento.

U ma outra importante tendência refere-se à clara inversão do peso respectivo das diferentes instituições que compõem o sistema de pesquisa no esforço total de $P \& D$, ou seja: o fortalecimento da pesquisa realizada nas universidades, em contraposição à desaceleração dos institutos de pesquisa especializados. No Reino Unido, por exemplo, os Research Councils racionalizaram seus institutos de pesquisa, reduzindo os financiamentos correspondentes; estes foram dirigidos para as universidades, que gozam de maior flexibilidade para atuar em novas áreas. $\mathrm{N}$ a França, essa tendência também é nítida, com o fortalecimento dos grupos de pesquisa no interior de institui ções de ensino superior (sobretudo das famosas grandes écoles) e 0 aumento de suas interações com o setor privado. ${ }^{12}$ As universidades alemãs,

\footnotetext{
${ }^{12}$ Enquanto que na época da implantação dos grands programmes technologiques os organismos públicos de pesquisa franceses trabalhavam direta ou quase que exclusivamente para os setores econômicos aos quais estavam associados, essas relações unívocas parecem ter desaparecido atualmente. Organismos como o CEA, o CNES e o CNET (nas áreas de pesquisa nuclear, espaço e telecomunicações, respectivamente) tendem orientar seus esforços em direção aos conhecimentos científicos de base, mantendo ao mesmo tempo os laços privilegiados com a comunidade de parceiros habituais.
} 
ao contrário, sofrem de uma certa estagnação dos recursos alocados em $P \& D$; nesse país, o setor não-acadêmico concentra quase a metade do total de recursos alocados no setor público de $P \& D$ e, de uma maneira geral, dispõe de melhores condições de infra-estrutura.

\subsection{Novos mecanismos de pilotagem das relações ciência-indústria}

D e uma maneira geral, as políticas de $C \& T$ têm evoluído na direção de quatro orientações centrais: a implementação desistemas deavaliação dos esforços de $P \& D$; a coordenação das atividades; a busca de ferramentas e novas metodologias para a definição de prioridades (planejamento estratégico); e o gerenciamento dos esforços de transferência de tecnologia. N os parágrafos a seguir, cada um desses aspectos será brevemente comentado.

M ecanismos deavaliação da pesquisa

A expansão das atividades de comercialização dos resultados das pesquisas, de um lado, e as decisões de orientação dos esforços de P\&D para aplicações industriais, de outro, estimularam o desenvolvimento e a adoção generalizada de novos sistemas de avaliação da $P \& D$, que trazem consigo mudanças importantesnos critérios de avaliação de pesqui sadorese instituições de pesquisa.

O Reino Unido e a França pertencem ao grupo de países onde a avaliação passou a fazer parte integral do sistema público de pesquisa. N 0 Reino Unido, a avaliação se realiza no interior do sistema de C\& T (por intermédio do Research Assessment Exercise) e seus resultadosinfluenciam diretamente a alocação de fundos para a pesquisa universitária e para os institutos de pesquisa. $\mathrm{N}$ a França, a avaliação está também ancorada no sistema nacional de $C \& T$, mas envolvendo mecanismos distintos para a avaliação das universidades, dos institutos de pesquisa e das agências especializadas. Já a Alemanha, assim como os países escandinavos, situa-se no grupo de países onde os esforços de avaliação são ainda parciais. A tendência atual é de que os institutos M ax Planck e a German Research Society introduzam procedimentos sistemáticos de self evaluation; discute-se também a introdução de um processo de avaliação do staff das universidades, que seria a base para deci sões de financiamento dos L änders. 
Finalmente, no que se refereà avaliação dos impactos das relaçõesciênciaindústria, considera-se que os exercícios realizados até o momento são dificilmentecomparáveis, sobretudo a nível internacional. Isso refletea ausência de um quadro metodológico comum e ao mesmo tempo eficaz para medir os inputs e outputs das iniciativas de colaboração. O s estudos disponíveis parecem interessar-se mais pela caracterização e pelas estratégias das partes envolvidas, do que pelos fatores que constituem o elemento motor dessas colaborações, ou pel os resultados concretos que são passíveis de mensuração. É consenso entre os analistas que as avaliações sobre os efeitos das RCI no processo de inovação são ainda limitados em número e em alcance.

N ovos efforços de coordenação do sistema

0 rápido avanço das $\mathrm{RCI}$ passa a demandar uma coordenação reforçada dos diferentes atores envolvidos. N os países onde instâncias regionais vêm desempenhando um papel cada vez mais importante no financiamento de atividades de $P \& D$, como na Alemanha e na França, a coordenação torna-se tanto mais necessária quanto mais complexa.

M aséno Reino U nido que certas experiências pioneiras de coordenação têm serevelado mais eficazes. Ao longo daúltima década, o país tem procurado fortalecer o processo de coordenação através de um conjunto de mecanismos específicos, como por exemplo a publicação anual de um Forward Look, contendo a descrição das atividades de pesquisa de cada departamento governamental, assim como uma avaliação da carteira de ativos financiados com fundos públicos. Por outro lado, os exercícios de prospecção tecnológica, que no início tinham um caráter predominantemente acadêmico, ganharam um novo edefinitivo impulso com a implementação do Technology Foresight Programme, que tornou-se um importanteinstrumento oficial de orientação e coordenação do sistema. O s R esearch C ouncils, por exemplo, são levados a considerar as prioridades identificadas pelo programa nas suas decisões sobre financiamento. Atualmente, ele é real izado periodicamente por intermédio de uma cooperação entre diferentes departamentos ministeriais e consultores externos. $^{13}$

\footnotetext{
${ }^{13}$ A esse respeito, ver Georghiou (1998) e Senker (1998).
} 
Em suma, a restrição orçamentária em matéria de $C \& T$ ea necessidade de recondução dos financiamentos públicos para novos setores de atividade, têm demandado a adoção de novas ferramentas e novas metodologias para a definição de prioridades de financiamento. À imagem da experiência inglesa, boa parte dos países da U E tem conduzido sistematicamente, com menor ou maior intensidade, exercícios prospectivos detipo forecasting ou foresight, como instrumentos de apoio ao processo de tomada de decisão e de formulação de políticas para o setor.

M ecani smosformais de interação com o setor industrial

I númeras experiências revelam que boa parte dos fracassos das RCI tem sua origem em "diferenças culturais" entre o mundo industrial e o mundo da pesquisa pública. Para tentar minimizar essas dificuldades e favorecer a cooperação, os poderes públicos vêm criando mecanismos para suprimir os obstáculos institucionaise regulamentares passíveis de bloquear essa cooperação e garantindo um ambientefavorável para o trabalho em parceria. 0 programa $\mathrm{H}$ igher Education W inning with Business (H EW B) foi lançado recentemente, no Reino U nido, com esse intuito, ou seja, favorecer a compreensão do mundo industrial pelo mundo acadêmico, através de programas específicos de treinamento e de desenvol vimento de projetos conjuntos (OCDE, 2002).

Por outro lado, a promoção do diálogo entre os setores público eprivado também tem se valido da implicação dos industriais em instâncias de decisão das instituições públicas de pesquisa. Alguns países, como o Reino Unido, têm adotado medidas visando engajar os potenciais usuários dos resultados das pesquisas realizadas com fundos públicos em todas as etapas do processo de formulação de políticas para o setor. A implicação deindustriais nos comitêse consel hos consultivos de instâncias governamentais, assim como na condução de programas de prospecção tecnológica, muito se fortaleceu na Europa nos últimosanos. Algumas agências gestoras de fundos defomento à $P \& D$ chegam a garantir a participação derepresentantes daindústria em instâncias deliberativas. Evoluções dessa natureza têm sido observadas no sistema alemão, onde representantes do setor industrial participam em instâncias de conselho e nas comissões setoriais da maior parte das instituições de pesquisa, tanto ao nível dos Länders, como no nível federal. 


\subsection{Avanço da colaboração na esfera regional (UE)}

$\mathrm{N}$ as últimas duas décadas, os governos dos países europeus passaram a fomentar diretamente colaborações internacionais em matéria de $C \& T$, baseadas em consórcios de pesquisa constituídos por instituições públicas e privadas e por industriais de diferentes países. Inúmeros programas multilaterais de pesquisa foram lançados nas esferas mundial e regional. D e forma bastante sintética, essas parcerias internacionais visam, fundamentalmente: atacar problemas planetários (mudança climática, exploração de fontes alternativas de energias, exploração do espaço, controle demográfico, etc.); promover a cooperação regional em matéria de $P \& D$; favorecer a transferência de conhecimentos dos países centrais para os países periféricos.

0 lançamento dos programas plurianuais de pesquisa e desenvolvimento tecnológico da União Européia, em meados dos anos 1980, inaugura porém umanova fase da cooperação $C \& T$ na região. Baseadosem projetos desenvolvidos por consórcios de pesquisa envolvendo no mínimo três equipes, ${ }^{14}$ provenientes deno mínimo dois países distintos, os programas da UE passam a ter um papel decisivo para o fortalecimento das RCI no continente(EC, 2000). V áriosestudos sobre os impactos desses programas nos sistemas nacionais de pesquisa e de inovação revelam que, apesar da modesta parcela que esses financiamentos representam nos gastos globais de $P \& D$ dos países membros, os programas da UE, pelo seu caráter cooperativo, têm influenciado direta ou indiretamenteas políticas nacionais no setor. A tendência geral éde um substancial aumento das colaborações realizadas entre os países da zona UE, em detrimento das colaborações destes com países de outros continentes (G usmão, 1997).

Por fim, os grandes organismos europeus de pesquisa, como o CERN CentreEuropéen pour la RechercheN ucléaire (em G enebra, Suíça), o ESFR European Synchrotron Radiation Facilities (em Grenoble, França), a ESA European Space Agency (com sedeem Paris), ou a EM BO - European M olecular Biology 0 rganization (em H eidelberg, Alemanha), permitem que determinados países mantenham suas competências em setores particulares da chamada big science e, ao mesmo tempo, oferecem um ambiente favorável para 0

\footnotetext{
${ }^{14}$ Em alguns casos, como no subprograma de novos materiais, esses consórcios podem reunir de 7 a 10 equipes, provenientes dos setores público, acadêmico ou privado.
} 
fortalecimento das RCI nesses setores epara a expan são de "redes de cooperação", congregando osprincipaisesforços públicos e privados de pesquisa do continente.

\section{Considerações finais}

Como tentamos demonstrar ao longo do artigo, as interações entre 0 sistema público de pesquisa eo setor industrial assumem formas institucionais diversas. Sua natureza eintensi dade divergem consideravelmenteentre os países, em função das particularidades e especificidades nacionais de cada um deles.

Em função das diferentes estruturas dos setores públicos de $P \& D$ e dos mecanismos de apoio à transferência de conhecimentos, que podem ser mais ou menos restritivos, os analistas da O CDE classificam os países membros em quatro grandes categorias (O CDE, 2002):

1. Países ondea parcela do financiamento e da execução públicos em $P \& D$ ébastante elevada no esforço nacional total:

- U niversity-based system: Turquia

- Broadly-based system: Itália, N ovaZelândia, Polônia, Portugal eM éxico

- Institute based system: H ungria, I slândia

2. Países ondea parcela do financiamento e da execução públicos em $P \& D$ érelativamente elevada:

- U niversity-based system:

Áustria espanha

- Broadly-based system:

França, H olanda eN oruega

3. Paísescom umataxamédia definanciamento eexecução públicosdaP\&D:

- U niversity-based system:

Canadá eReino U nido

- Broadly-based system:

Dinamarca, Finlândia eAlemanha

- Institute-based system:

RepúblicaT checa

4. Paísescom umataxa reduzida definanciamento eexecução públicosdaP\&D:

- U niversity-based system:

Estados Unidos, Japão, Suécia, Suíça,

- Institute based system: Bélgica elrlanda

Coréia 
$N$ esse contexto, de acordo com esses analistas, o principal desafio do primeiro grupo de países, ondea intensidade deP\& $D$ situa-se abaixo da média, seria o demelhorar as capacidades tecnológicas das firmas eaumentar o esforço global deP\& $D$ em benefício do setor privado. O spaíses do segundo eterceiro grupos deveriam, por sua vez, intensificar as RCI com o objetivo de aumentar os esforços da pesquisa pública em função das necessidades do setor industrial nacional. Ao quarto grupo seria altamente recomendável procurar manter 0 nível de excelência da pesquisa acadêmica e reforçar um setor público de pesquisa e desenvolvimento fragilizado pela retração dos investimentos.

As informações e práticas internacionais que se procurou aqui sistematizar, sugerem que o model o hierárquico e centralizado de condução das relações ciência-indústria, que preval ecia na maior parte dos países, tem evoluído para um modelo de natureza "contratual" e descentralizado. N as colaborações entre o setor público de pesquisa e o setor privado, a balança do poder tende a deslocar-se para o lado das firmas e dos interesses e estratégias industriais; no âmbito das instâncias governamentais, o poder vem passando das autoridades centrais para as autoridades regionais e locais; no interior do setor público deP\& D, dos institutos de pesquisa às universidades; eno interior dasinstituições de pesquisa, da administração central aoslaboratórios, unidades ou oficinas especializadas.

D e qual quer maneira - e essa é a principal conclusão que retemos do exercício comparativo da OCDE, referenciado ao longo do artigo - as instituições públicas de pesquisa, as universidades e as empresas industriais revelam-se em ótimas condições para determinar a melhor maneira de intensificar suas interações eatividades de cooperação na prática. N a verdade, são os governos que têm a responsabilidade de estabel ecer as regras básicas, os marcos institucionais e os incentivos mais adequados que devem ser concedidos às empresas eàs instituições de pesquisa. A ação política é portanto considerada de extrema importância e, para a totalidade dos países, imprescindível ao bom desempenho das $\mathrm{RCI}$ e deseu impacto sobre o processo deinovação.

$N$ esse sentido, a título de conclusão, sintetizamos abaixo as principais implicações políticas e recomendações que emanam dos trabal hos da O CDE sobre 0 assunto, que foram amplamente discutidas na Conferência 
Internacional Benchmarking I ndustry-Science Relationships, realizada em Berlim em 2000,15 e em outros importantes foros da 0 rganização.

- assegurar um quadro adequado para a proteção dos direitos de propriedadeintelectual, com a fixação deregrase orientações claras relativas aos direitos da instituição executora e, ao mesmo tempo, garantindo aos pesquisadores o recebimento de uma participação nos royalties;

- melhorar a gestão das RCI nas universidadesenosinstitutos depesquisa, através da adoção, dentre outros recursos, de atividades regulares de prospecção tecnológica e denovos instrumentos voltados à identificação edefinição de prioridades que reflitam as necessidades da indústria;

- promover efortalecer a implicação das PM E no processo de inovação, eestimular a criação de spin-offs, como meio quepermiteàs universidades estender amplamente suas licenças de tecnologia;

- atrair ereter recursoshumanosqualificados, com vistasa manter talentos e evitar a "fuga de cérebros"; isso implica perspectivas de melhora profissional esalarial, ea garantia de boas condições para o exercício das atividades de pesquisa;

- eliminar as barreirasea falta de incentivosao treinamento ou al ocação temporária de pesquisadores do setor público e de universitários nas empresas, por intermédio de reformas legislativas ou da flexibilização do regime detrabal ho desses pesquisadores;

- melhorar efortalecer os esforços deavaliação da P\&D pública, com a adoção de novos critérios que considerem os esforços de comercialização dos resultados das pesquisas realizadas nas universidades e nos institutos depesquisa;

\footnotetext{
15 Joint German-OECD Conference on Benchmarking Industry-Science Relationships, realizada em Berlim nos dias 16 e 17 de outubro de 2000, co-organizada pela OCDE e pelo Ministério da Educação e Pesquisa da Alemanha (BMBF) (ver www.oecd.org/sti/innovation).
} 
- responder à global ização das atividades de P\& D , através da abertura dos programasnacionaisà participação deempresas estrangeirase da criação de novos estímulos para que os institutos de pesquisa e universidades fortaleçam seus vínculos com empresas estrangeiras;

- reforçar as atuais estruturas cooperativas de inovação, fazendo com que o fomento às RCI esteja articulado com uma estratégia política global de inovação baseada em pól os e em redes.

\section{Bibliografia}

Beise, N .; Stahl, H ., "Public research and industrial innovations in Germany", Research Policy 28, p. 397-422, 1999.

Cassier, M ., "Compromis institutionnels et hybridations entre recherche publique et recherche privée". Revue d'Economie Industrielle n. 79, $1^{\text {er }}$ trimestre, 1997, p. 191-212, 1997.

Cervantes, M., "Les partenariats public-privé dans les domaines scientifique et technologique: Tour d'horizon". OCDE - STI Revue, n. 23, p. 7-24, 1998.

CGP., Recherche et innovation: la France dans la compétition mondiale. Commissariat Général du Plan. Paris: La D ocumentation Française, 440p., 1999.

EC., Vers un espace européen de la recherche. Communication de la Commission au Conseil, au Parlement Européen, au ComitéEconomique et Social et au Comité des Régions. Bruxelles: CCE 999109-C, 37p., 2000.

EC., Second European report on S\& T indicators. Luxembourg : O ffice des Publications 0 ficielles des Communautés Européennes, 1997.

ESTA., Academic and Industrial Research C o-operation in Europe European Science and Technology Assembly. EC - Luxembourg (Working Paper), 1997.

Faulkner, W., "G etting behind industry-public sector research linkage: a novel research design". Science and Public Policy, v. 22, n. 5, p. 282-294, 1995. 
Geourghiou, L., The U nited Kingdom N ational System of Research, Technology and Innovation. Commissariat Général du Plan - Groupe "Analyse des Systèmes Nationaux de Recherche"/France, 35p. (D ocument de travail), 1998.

Gusmão, R., L'engagement français dans l'Europe de la recherche. Paris: Ed. Economica, 291p., 1997.

$M$ ansfield, E., "Academic research and industrial Innovation: an Update of Empirical Findings". Research Policy, 26, p. 773-776, 1998.

M eyer-K rahmer, F., The German Innovation System. Commissariat Général du Plan - Groupe "Analyse des Systèmes N ationaux de Recherche", France, 42p. (D ocument de travail), 1998.

; Schmoch, U., "Science-based technologies: university-industry interactions in four fields". Research Policy 27, D ecember, Issue 8, p. 835851, 1998.

M owery, D., The Changing Structure of the U.S. National Innovation System. Commissariat Général du Plan - Groupe "Analyse des Systèmes N ationaux de Recherche", France, 39p. (D ocument de travail), 1999.

$\mathrm{N}$ arin, F. et al., "The increasing linkage between U.S. technology and public science". Research Policy 26, p. 317-330, 1997.

OCDE, Benchmarking Industry-Science Relationships. Paris: OECD Publications, 198p., 2002.

- Industry-Science Relations: Interim Report. OECD Working Group on Innovation and Technology Policy. DSTI/STP/TIP(2000)6, 39p., 2000.

, Benchmarking Indicators. OECD Working Group on Innovation and Technology Policy. Room Document 2, 1999a.

- Benchmarking Industry-Science Relationships and Research-Based SpinO ffs. Working G roup on Innovation and Technology Policy. D ST I/ST P(99)25, 1999b.

, "La définition des subventions à la $R \& D$ et à l'innovation industrielle". STI Revue n. 21, p. 117-155, 1998a.

, "Les partenariats de recherche entre l'industrie et les universités: un panorama". OECD - STI Revue, n. 23, p. 43-74, 1998b.

"Tendances et caractéristiques des aides publiques à l'industrie dans la zone de I'OECD ". STI Revue, n. 21, p. 15-28, 1998c. 
An Empirical Comparison of $\mathrm{N}$ ational Innovation Systems: Various Approaches and Early Findings. OECD Working Group on Innovation and Technology Policy. DSTI/ST P/TIP(97)13, 46p., 1997.

OST, Relations recherche publique - activité industrielle. Pratiques et politiques internationales du partenariat en R\&D. OST-INRA (Rapport Final réalisé par Regina Gusmão), octobre, 51p., 2000.

Pretschker, U., "Les aides publiques en faveur de la R\&D industrielle". OECD STI Revue, n. 21, p. 101-116, 1998.

Sato, Y., The Structure and Perspective of Science and Technology Policy in Japan. Commissariat Général du Plan - Groupe "Analyse des Systèmes N ationaux de Recherche", France, 52p. (D ocument de travail), 1999.

Senker, J. et al., European Comparison of Public Research Systems. CE-TSER Project N SOE1 - CT 96 - 1036. Brighton: SPRU, 68p., 1999.

, "Raison d'être des partenariats : mise en place des systèmes nationaux d'innovation". OECD - STI Revue, n. 23, p. 25-42, 1998. 